\title{
COMMISSIONING OF THE LNLS 500-MEV BOOSTER SYNCHROTRON
}

\author{
R.H.A. Farias, M. J. Ferreira, G.S. Franco, A.C. Lira, Liu Lin, R.T. Neuenschwander, C. Pardine, \\ A.C. Rosa, C. Scorzato, P.F. Tavares, G. Tosin, LNLS, Campinas, Brazil
}

\begin{abstract}
We present results of the commissioning of a new injector for the Brazilian Synchrotron Light Source. The new injector consists of the existing 125-MeV LINAC and a new $500-\mathrm{MeV}$ booster synchrotron. At present, about $40 \mathrm{~mA}$ can be injected into the booster and about $15 \mathrm{~mA}$ can be ramped up to $500 \mathrm{MeV}$ at a repetition rate of $0.17 \mathrm{~Hz}$. The new injector has allowed the accumulation of up to $540 \mathrm{~mA}$ in the main ring at 500 $\mathrm{MeV}$ and up to $305 \mathrm{~mA}$ has been ramped up to the storage ring nominal energy of $1.37 \mathrm{GeV}$. The new beam intensity is more than twice as large as the typical stored beam current before the installation of the booster synchrotron.
\end{abstract}

\section{INTRODUCTION}

The Brazilian National Synchrotron Light Laboratory (LNLS) has recently built and commissioned a 500-MeV booster synchrotron as part of a new injector for the LNLS synchrotron light source. The new injector allows an increase of the injection energy into the LNLS 1.37$\mathrm{GeV}$ electron storage ring, which has been running routinely for synchrotron radiation research since July 1997. The decision to upgrade the injection energy arose from the need to install small gap insertion devices and also to further increase the stored beam current by improving injection efficiency. Typically the stored beam current at $1.37 \mathrm{GeV}$ before the installation of the booster synchrotron was $140 \mathrm{~mA}$, and a record $540 \mathrm{~mA}$ stored beam current has been achieved in the storage ring at the new injection energy. Limitations in the storage ring RF and vacuum systems currently limit the maximum current that can be ramped to full energy to about $300 \mathrm{~mA}$.

Following the same strategy used in the construction of the LNLS LINAC and storage ring, we have decided to design and build most of the hardware for the new injector in-house, including all DC and pulsed magnets, power supplies, pulsers, vacuum chambers, cooling, control (both hardware and software) and timing systems. The RF system, including four $250-\mathrm{W}$ amplifier modules at $500 \mathrm{MHz}$ was also developed and constructed at LNLS in collaboration with the LURE RF group [1]. This allowed us to deliver a 500-MeV machine in about 2 and a half years for less than US\$2M. Significant items contracted out to industry and other suppliers include the RF cavity, vacuum pumps and gauges and beam instrumentation (beam position and current monitors).

The previous injector (a $125-\mathrm{MeV}$ LINAC) is now the preinjector into the booster, but the low energy injection scheme (LINAC into ring) was kept operational during the booster construction and installation period (about two years), thus minimizing the downtime for synchrotron radiation users. This was accomplished by modifying the LINAC-to-storage ring transport line so that it can direct the beam either directly to the storage ring or to the booster. Once the booster is fully operational, the LINAC-to-storage ring transport line can be removed and the corresponding injection straight made available for the future installation of insertion devices.

The booster synchrotron was built to provide not only a reasonable beam intensity for filling the storage ring in a short time but it was also designed to allow its use as a small storage ring for future beam dynamics experiments. Although its design repetition rate is fairly low $(0.2 \mathrm{~Hz})$, the total design current $(70 \mathrm{~mA})$ is high enough to allow experiments to be conducted in storage mode.

Table I shows the main machine parameters. A detailed account of the machine conceptual design and the rationale for the choice of the main parameters is given in [2] whereas details on the development of the main subsystems are given in [3]. Reports on other subsystems are also presented at this conference[4][5][6][7][8][9]. In this report, we concentrate on the results of commissioning with beam, the implementation of the energy ramp and optical characterization of the booster synchrotron.

Table I: Injector ring main design parameters.

\begin{tabular}{|c|c|}
\hline 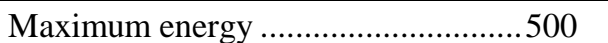 & $\mathrm{MeV}$ \\
\hline Injection energy........ & $\mathrm{MeV}$ \\
\hline Circumference....... & $\mathrm{m}$ \\
\hline RF frequency ...................................... & $\mathrm{MHz}$ \\
\hline 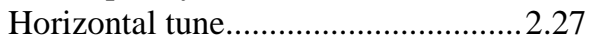 & \\
\hline Vertical tune & \\
\hline Repetition rate & $\mathrm{Hz}$ \\
\hline
\end{tabular}

\section{BOOSTER COMMISSIONING}

All booster components, including magnets, power supplies, vacuum chambers, controls, RF, timing and diagnostic systems were finished and installed in a series of short shutdowns (interspersed with routine machine operation for synchrotron radiation users) that extended from May to November 2000. Actual commissioning of the injector started on November $24^{\text {th }}$ and two days later the first turn in the booster synchrotron was observed. The advances continued quickly and beam capture in the booster was demonstrated, first for a coasting beam 
without RF power (November $27^{\text {th }}$ ) and then with $200 \mathrm{~W}$ of RF power allowing the accumulation of $8 \mathrm{~mA}$ of beam current in a single LINAC pulse (November $28^{\text {th }}$ Figure 1).

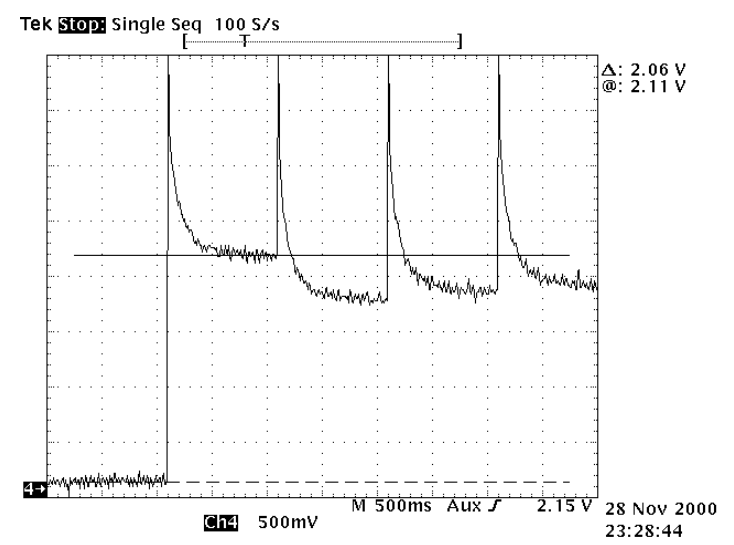

Figure 1: Current captured in the booster synchrotron at $125 \mathrm{MeV}$. Vertical scale is $2 \mathrm{~mA} / \mathrm{div}$.

At first only a limited amount of RF power was available, since only a single RF amplifier module was installed. This was however enough to allow beam capture and debugging of the main aspects of the machine optics at injection energy. Ramping to the maximum booster energy was first accomplished on December $22^{\text {nd }}$ and on the next day the extracted beam was observed in a toroidal beam current transformer right after the thick extraction septum. From January to March, routine operation for synchrotron users resumed (with injection taking place directly from the LINAC) and the commissioning of the various booster subsystems continued in parallel. Various improvements during that period, in particular the addition of more RF amplifier modules (which raised the total available RF power to $900 \mathrm{~W}$ ) and changes to the control network topology and high level software as well as machine optimization led to the capture of up to $40 \mathrm{~mA}$ in a single LINAC pulse and the implementation of repetitive booster ramping cycles at $0.17 \mathrm{~Hz}$ repetition rate with about $15 \mathrm{~mA}$ of current ramped up to $500 \mathrm{MeV}$. A scan of tunes searching for optimum beam capture in the booster conditions led to values $(\mathrm{Qx}=2.13 \mathrm{Qy}=1.19)$ closer to the coupling resonance than the design values. The measured dispersion function is in good agreement with the theoretical expectations (Figure 2). Extraction at 500 $\mathrm{MeV}$ was demonstrated with up to $100 \mathrm{~ns}$ long bunch trains (out of the $113 \mathrm{~ns}$ booster circumference) being observed at a current monitor after the thick extraction septum. The total measured extracted charge @ $500 \mathrm{MeV}$ is about $1 \mathrm{nC}$ (Figure 3).

With booster debugging well under control, user's operation was stopped again in April 2001 to allow for the installation of the booster-to-storage ring transport line as well as changes to the storage ring vacuum chambers in the new injection straight, including new stronger injection kickers. Installations were completed on April $12^{\text {th }}$ and about 12 hours later the first turn in the ring at $500 \mathrm{MeV}$ was observed. Another twelve hours went by before beam accumulation was demonstrated in the storage ring at the new injection energy and a few days later the stored current record was broken. Injection of beam currents above $200 \mathrm{~mA}$ in the storage ring has also been demonstrated with a $10 \mathrm{~mm}$ gap in the vacuum chamber. As higher currents were stored in the ring, the threshold for transverse (vertical) instability was crossed and a blowup in the vertical plane could be observed on a synchrotron radiation monitor, although this could be tolerated by the ring aperture. In some cases (apparently depending on the bunch filling pattern in the storage ring), the vertical blowup leads to current loss at injection. This effect is not quite reproducible and is currently under study.

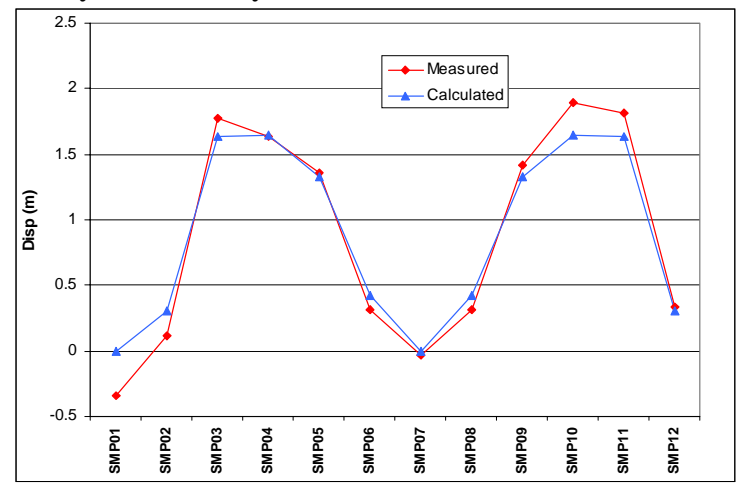

Figure 2: Measured and calculated dispersion function in the booster.

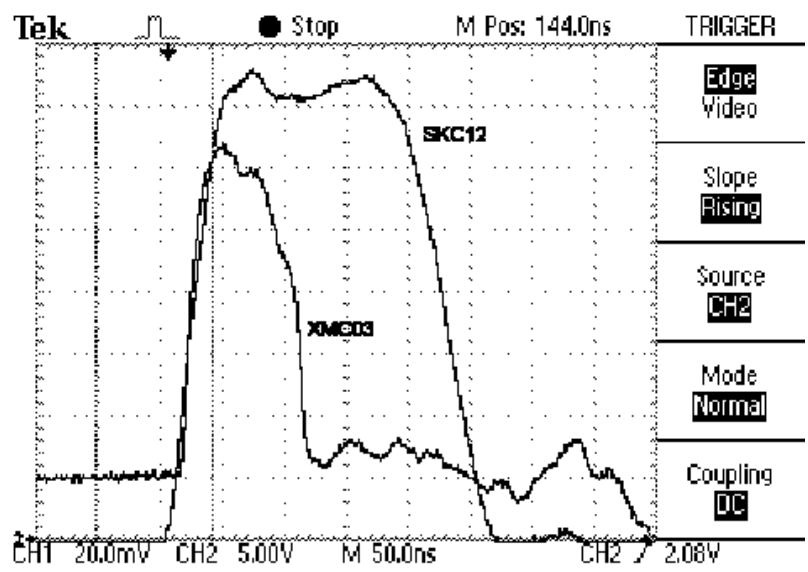

Figure 3: Extracted current pulse observed right after the thick extraction septum (XMC03). Vertical scale 3.4 $\mathrm{mA} /$ div. Also shown is the extraction kicker current pulse (SKC12).

\section{BOOSTER ENERGY RAMP}

The energy ramp in the booster is done in basically the same way as in the storage ring: all magnet power supplies are ramped by local controllers which deliver reference voltages to be tracked by the power supplies. 
These local controllers are kept in synchronism by means of trigger signals, which interrupt the many controllers' CPUs simultaneously causing them to implement previously calculated ramping steps stored in a ramping table in the local controller's memory. This process allows enormous flexibility in the ramping curves for the various power supplies but also implies some limitation in the maximum attainable repetition rate or ramping speed. The limitations related to the response time of the local controllers depend on the number of steps into which the ramp is divided. This can be configured in the high level software and at present we are using 1024 points (for the dipole, quadrupole and sextupole power supplies), which also limits the total ramping time to about 1.9 seconds. Figure 4 shows an example of an energy ramp in the booster. Most of the current losses take place at the very beginning of the ramp.

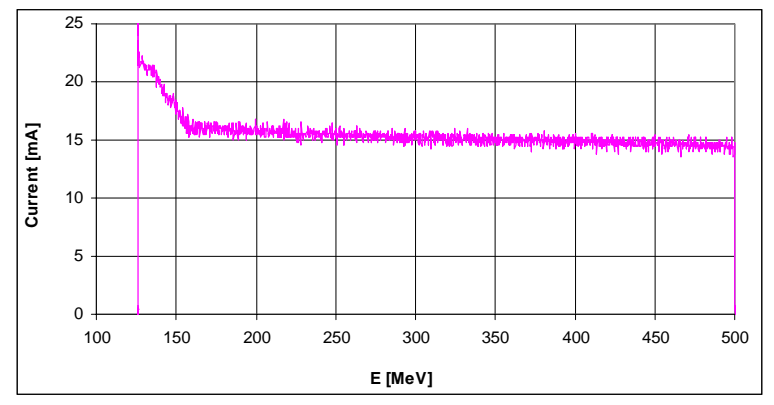

Figure 4: Energy ramp in the booster synchotron.

One important difference between the ramping procedure in the booster as compared to that in the storage ring is that the storage ring ramp is initiated by an operator command and ramping speed changes along the ramp as well as the detection of the end of the ramp are handled by the high level system. In the booster energy ramp, the ramping start, speed changes and ejection are all handled by the low level control system, which is previously configured by the high level system with parameters that define all aspects of the ramp to be executed (e.g. table of ramping speeds, point of ejection). The ramping procedure configuration includes a threshold current (the minimum current captured in the booster that is considered worth ramping) and a time delay which designates how much time after the injection pulse the booster current is measured in order to decide whether the ramping will begin. In the event of a poor injection pulse, the ramping is not started and new LINAC pulses are injected until enough current is captured. This procedure guarantees that the (relatively long) ramping time will only be spent once a sizable amount of current is captured in the booster.

\section{EXTRACTION FROM THE BOOSTER}

The main challenge in extracting the beam from the booster is the short revolution period (113 ns) which demands a very fast rise time $(40 \mathrm{~ns})$ for the extraction kicker pulser. In order to alleviate the voltage needed for the extraction kicker, extraction is made by first distorting the horizontal orbit with corrector magnets during the energy ramp so as to bring the beam closer to the septum wall. This DC orbit bump is responsible for up to $16 \mathrm{~mm}$ orbit deviation at the extraction septum position and the remaining $12 \mathrm{~mm}$ is then produced by the fast kicker. The kicked beam is then directed to the booster-to-storage ring transport line by means of two pulsed septa. The thin septum is a ferrite C-magnet with a combination of active shielding (provided by a thin current sheet) and passive shielding provided by a copper tube forming the booster vacuum chamber. The thick septum has a similar design but originally only active shielding was provided. Experiments with the beam demonstrated the need to add passive shielding in the form of a copper tube around the stainless steel booster vacuum chamber.

\section{CONCLUSIONS}

A $500-\mathrm{MeV}$ booster synchrotron has been built as an improved injector for the LNLS synchrotron light source. The commissioning of the new injector was quick and no major difficulties were met in achieving the required beam energy and intensity for injection into the storage ring. As a result the beam intensity in the storage ring is now more than twice as large as the typical values before the installation of the booster.

\section{ACKNOWLEDGEMENTS}

We gratefully acknowledge the support of the LNLS technical and administrative staff, which was essential for the timely completion of this project.

\section{REFERENCES}

[1] R.H.A. Farias et al, RF System for the LNLS Injector Synchrotron, these Proceedings.

[2] A.R.D.Rodrigues et at, Design of a Booster for The Brazilian Synchrotron Light Source, EPAC 98.

[3] Liu Lin at al, Status of the LNLS booster Project, Particle Accelerator Conference PAC 1999 New York.

[4] C. Scorzato et al, Upgrade of the LNLS Synchrotron Light Source Timing System. These Proceedings.

[5] P. Tavares et al, Dipole Magnets for the LNLS 500-MeV Booster Synchrotron. These Proceedings.

[6] M.J. Ferreira et al, Vacuum System for the LNLS 500-MeV Booster Synchrotron. These Proceedings.

[7] A.C. Lira et al, Power Supplies for the LNLS 500$\mathrm{MeV}$ Booster Synchrotron. These Proceedings.

[8] A.C. Lira et at, Septum and Kicker Pulsers for the LNLS 500-MeV Booster Synchrotron. These Proceedings.

[9] J.R. Piton et al, Control and Diagnostic Systems for the LNLS 500-MeV Booster Synchrotron. These Proceedings. 